DOI: $10.17805 /$ zpu.2017.3.5

\title{
Самореализация личности по возрастным интервалам (на примере современных россиян)
}

\author{
Т. 3. КОЗЛОВА \\ ИНСТИТУТ СОЦИОЛОГИИ РОССИЙСКОЙ АКАДЕМИИ НАУК
}

Самореализация человека - главная цель всей его жизни. Жизненный путь человека непрерывная цепь этапов самореализации. Самореализация личности - это актуализации индивида в двух основных сферах жизни: профессии (труде) и семье человека. Объект исследования - возрастные группы граждан России (в возрасте от 18 лет и старше): 1) «18-30 лет»; 2) «31-40 лет»; 3) «41-50 лет»; 4) «51-60 лет»; 5) «старше 60 лет». Возраст является важной характеристикой личности. Он - индикатор биологического и психологического статуса человека, а значит, в определенной степени его социальной активности. С возрастом происходит снижение умственных способностей и сужение сферы мотивации. Этот тезис подтвержден в исследованиях западных ученых (Р. Кюлен, Б. Ньюгартен и др.). Предмет исследования - самореализация личности. Сферы профессиональной деятельности являются теми институтами, где реализуется личность. Ответ на вопрос, каков уровень самореализации лиц различных возрастных групп, автор статьи получила, анализируя репрезентативное Всероссийское социологическое исследование, которое провел Институт социологии РАН в конце 2016 г. Выборка - 4000 человек. Респондентам был задан вопрос: «Оцените по 5-балльной шкале, насколько важным лично для Вас на сегодняшний день является: самореализация, проявление себя». На шкале от 1 до 5 определены значения: «не важно» - для оценки 1; «важно» - для оценки 4; «очень важно» для оценки 5. Самореализацию мы определяем суммой двух оценок 4 и 5. Каков уровень самореализации личности по возрастным группам? У респондентов самой молодой возрастной группы «18-30 лет» сильная мотивация и умственные способности на пике развития. У них высокая самореализация - 87\%. Второй интервал взрослой жизни - человек от 31 года до 40 лет, период наиболее активной реализации поставленных целей. У них также высокая самореализация - 83\%. Третий возрастной период жизни человека - возраст после 50 лет. Человек стремится свои знания передать молодежи. Самореализация в этой возрастной группе - 74\%. Предпенсионный период («51-60 лет»). Уход на пенсию сопряжен для многих людей с определенными переживаниями. Для возрастной группы «51-60 лет» самореализация - 73\%. В возрастной группе «60 и старше» у людей подтачиваются силы, самореализация понижается до 56\%.

Ключевые слова: возраст; возрастные интервалы; социальная группа; самореализация; личность; мотивация; способности

\section{ВВЕАЕНИЕ}

B статье рассматриваются две взаимосвязанные темы: самореализация личности и возрастные интервалы ее социального времени. Научная проблема - самореализация личности в течение жизни (в различные возрастные периоды). Социальная проблема - самореализация наших современников по возрастным интервалам.

Материалы для написания статьи взяты из Всероссийского социологического исследования, проведенного в 2016 г. Аанные этого исследования были использованы автором в ранее написанной статье при анализе старшего поколения (Козлова, 2017).

\section{САМОРЕААИЗАЦИЯ АИЧНОСТИ}

Самореализация человека - главная цель всей его жизни, его социального времени. Жизненный путь человека - непрерывная цепь әтапов самореализации. «Смысл жизненного пути состоит в самореализации индивидов. Способы самореализации индивидов и есть формы объективирования смысла их жизни» (Грибакин, 1985: 196). 
Самореализация личности - это актуализации индивида в двух основных сферах жизни: профессии (труде) и семье человека.

Самореализацию личности мы рассматриваем с момента примерного завершения процесса социализации индивида (18 лет), т. е. самореализацию взрослого человека, готового принять участие в жизни общества, в профессиональной деятельности. Человек вначале своего взрослого пути определяет цели (смысл) своей жизни, исходя из своих потребностей. Высшими потребностями личности (по А. Маслоу) являются потребности в самоактуализации, самореализации. Сюда относятся потребности в достижении тех потенций, на которые способен человек, потребности в саморазвитии, в творчестве в широком смысле этого слова (Маслоу, 1999). Поставив перед собой цели, индивид сопоставляет их со своими способностями и возможностями.

Вступая в период взрослости, «человек наиболее полно раскрывает свои потенции и задатки, возможности и способности. Своим продуктивным трудом он пополняет ресурсы, возможности общества. Такой человек особенно нужен обществу, ибо поддерживает его существование, приумножает его потенциал. Получив образование, воспитание, профессию, он теперь отдает обществу то, что получил от него. Разумеется, такой нормативный вариант самореализации подготавливается всеми предшествующими фазами развития» (Зобов, Келасьев, 2008: 231).

Сферы его профессиональной деятельности являются теми институтами, где реализуется личность. Аеятельность в них, рассмотренная по временным интервалам, этапы самореализации личности. Общая направленность личности (ее диспозиция) регулирует деятельность индивида. Высший диспозиционный уровень личности включает в себя социальные установки (ценностные ориентации) на цели жизнедеятельности и средства их достижения.

Итак, в течение жизни человек проходит несколько этапов жизни (возрастных интервалов). Надо отметить, что основой классификации отдельных периодов жизненного цикла человека является признание противоречивого единства: биологического и социального. Соответственно изменениям биологического состояния человека происходят изменения его социально-психологических характеристик, причем послеАние оказывают воздействие и на процессы физического старения, сдерживая или ускоряя его. С возрастом происходит снижение умственных способностей и сужение сферы мотивации.

Построить концепцию мотивации, основанную на анализе возрастных возможностей личности, попытались американские психологи (Kuhlen, 1968). Они предложили две модели мотивации, характерные для различных возрастных периодов жизни. Первая модель для молодого и зрелого возраста (20-50 лет), когда человеку сопутствуют достижение целей и успех. В этот период жизни происходит расширение сферы потребностей, а вместе с ней и сферы мотивации. У молодых людей наблюдается активное стремление добиться цели, ориентация на достижение успеха во всем: в карьере, экономической обеспеченности и пр. Формируется потребность «быть впереди». Вторая модель - для человека в пожилом и преклонном возрасте. В этот период происходит сужение сферы потребностей, а вместе с ней и сферы мотивации. У старых людей ухудшается здоровье, они становятся менее энергичными и начинают «перемещаться» от более значительных и успешных ролей к менее значительным и успешным. Если в молодые годы для психологического равновесия личности необходима активная деятельность, то в старом возрасте у большинства людей это равновесие сопровождается пассивностью, мотивацией «к отставке», которая является средством из- 
бежать страха в предчувствии социального отвержения. У старых людей мера тревоги в значительной степени зависит от самооценки, которая тесно связана с уровнем самореализации.

Наряду с изменением сферы мотивации с возрастом изменяется и вторая группа психических свойств - умственные способности. Западные ученые (Аж. Биррен, Аж. Ботвинник, А. Векслер и др.), исходя из результатов проведенных ими исследований, пришли к выводу, что с возрастом происходят прогрессивные изменения умственных способностей людей (исключая речь и словарный запас). Однако, по их мнению, у отдельно взятых людей некоторые способности могут сохраняться до глубокой старости. Речь идет о гетерохронности в отношении умственных способностей (Botwinick, 1967). Некоторые геронтологи склонны рассматривать жизненный путь как трехфазовую схему: подготовительный период (социализация), активный период (до пенсии), фаза покоя - пенсионный период (Clemens, Backes, 1998).

\section{АИНАМИКА САМОРЕААИЗАЦИИ}

Каков уровень самореализации лиц различных возрастных групп, как он меняется с возрастом? Ответ на этот вопрос автор статьи получила в исследовании Института социологии РАН 2016 г. Объект нашего исследования - возрастные группы граждан России (в возрасте от 18 лет и старше). Перечислим их: 19-30 лет; 31-40 лет; 41-50 лет; 51-60 лет; старше 60 лет. Мы берем градацию по возрастным группам, предложенную психологом Б. Г. Ананьевым (Ананьев, 1977: 341-344).

Предмет исследования - самореализация личности. Эмпирическая база - репрезентативное Всероссийское социологическое исследование, которое провел Институт социологии РАН в конце 2016 г. Выборка - 4000 человек.

Респондентам был задан вопрос: «Оцените по 5-балльной шкале, насколько важным лично для Вас на сегодняшний день является: самореализация, проявление себя». На шкале от 1 до 5 определены значения: «не важно» - для оценки 1; «важно» - для оценки 4; «очень важно»- - ля оценки 5.

Рассмотрим уровень самореализации личности по возрастным группам, обозначенным выше.

Первый интервал взрослой жизни от 18-30 лет (в зависимости от окончания получения образования). У личности поставлены жизненно важные цели, сформировался план их выполнения. Определение генеральной цели (дерева целей) жизни является важным событием первой стадии самореализации личности. Вместе с тем первый этап реализации личности прежде всего связан с процессом адаптации как в профессии, так и в семье (если она уже создана). Анализ әмпирического исследования показал, что у этой возрастной группы $30 \%$ респондентов отметили, что самореализация для них «важна», а 57\% подчеркнули, что самореализация для них «очень важна». Итак, $87 \%$ молодых людей, входящих в социальную жизнь, считают, как важно становление их личности, самореализация. Это факт говорит о том, что у молодых людей большое стремление добиться поставленной цели. У них сильная мотивация, умственные способности на пике развития. Они стремятся к своей самореализации. У старших возрастных групп уровень самореализации несколько меньше. Возраст «18-30 лет» у них уже позади.

Второй интервал взрослой жизни - человек в возрасте от 31 до 40 лет. Освоена профессия. Это период расцвета всех жизненных сил, период наиболее активной реализации поставленных целей. Ученые Санкт-Петербургского университета Р. А. Зо- 
бов и В. Н. Келасьев так пишут об этом возрастном периоде в жизни человека: «Продолжается профессиональный рост, означающий самореализацию. В случае социальной успешности повышается общая мотивация, происходит творческое развитие средствами профессии. Субъективно этот возраст переживается как апогей жизни, эти годы - период оптимума профессиональных достижений. На этой фазе обнаруживается различие стилей жизни, критериев жизненного успеха. В целом же возраст 30-40 лет характеризуется как время накопления относительно постоянных материальных средств и социальных связей, лидерства в различных видах деятельности» (Зобов, Келасьев, 2008: 233).

Анализ эмпирических данных исследования показал, что у этой возрастной группы $38 \%$ респондентов отметили, что для них «важна» самореализация, а $45 \%$ подчеркнули, что «очень важна». Итак, для 83\% респондентов возрастной группы 41-50 лет самореализация «важна» и «очень важна». Это тоже высокий показатель самореализации личности в этом возрасте, хотя несколько ниже, чем в предыдущем. Это возраст профессиональной зрелости, когда еще достаточно хорошее здоровье, достаточно сил. В этот период человек отдает накопленные ранее знания, передает свой опыт более молодым коллегам. Среди людей этой возрастной когорты много руководителей в разных сферах производства и науки. Итак, у этой возрастной группы также высокий уровень самореализации личности, хотя он несколько меньше, чем у предыдущей (более молодой) группы.

Третий период взрослой жизни человека - возраст после 50 лет. В профессиональной деятельности человек достигает высшей квалификации. Человек знает, что стоит в преддверии пенсии. Поэтому, как никогда, он стремится передать другим, более молодым сотрудникам свои знания и умения. Аля него самореализация в этот период - увидеть, что его ученики переняли его опыт, достигли совершенства в профессии. Анализ эмпирических данных исследования показал, что у этой возрастной группы $34 \%$ респондентов отметили, что для них «важна» самореализация, а $43 \%$ подчеркнули, что «очень важна». Итак, для 74\% респондентов возрастной группы 41-50 лет самореализация «важна» и «очень важна».

Предпенсионный период и сам уход на пенсию сопряжены для многих людей с переживаниями. А именно: у работающего человека сложился определенный образ жизни, который придется ломать (в случае ухода на пенсию). На службе он занимает какую-то позицию, постоянно общается с коллегами, имеет определенный социальный статус. С уходом на пенсию все это человек теряет, не говоря уже о потере зарплаты. Конечно, есть ряд людей, с удовольствием уходящих на пенсию. Скажем, человек не любит свою работу, плохо себя чувствует и другие причины. Но для большинства людей уход на пенсию - это испытание, снижение самооценки, которая тесно связана с уровнем самореализации человека (Козлова, 2003). Чтобы этого не произошло, люди и в пожилом возрасте продолжают работать. Не всегда это происходит изза недостатка материальных средств. Некоторые пенсионеры не хотят покидать свою работу, даже если им материально помогают дети. По данным Росстата, среди мужчин пенсионного возраста продолжают работать в возрасте $60-72$ лет $4,7 \%$ от всех занятых в экономике, среди женщин в возрасте 55-59 лет - 8,7\%, в возрасте 60-72 лет5,0\% (Социальное положение ..., 2015: 62).

В старшем возрасте, выйдя на пенсию, каждый хочет быть полезным, т. е. хочет себя реализовать. Если пенсионер не работает на государственной службе, то воспитывает внуков, помогает ухаживать за нездоровыми родственниками. Некоторые 
пенсионеры участвуют в патриотическом воспитании молодежи, занимаясь в Советах ветеранов.

Каков уровень самореализации лиц старшего возраста, как он меняется в старшем возрасте? Как и предполагалось, для лиц возрастной группы 51-60 лет самореализация «важна» для 36\% респондентов и «очень важна» для 37\%. Итак, для возрастной группы 51-60 лет самореализация «важна» и «очень важна» для 73\% человек. Что соответствует действительности, так как в эту возрастную группу входят мужчины еще не пенсионного возраста, т. е. работающие (за исключением инвалидов и безработных). Женщины в этой группе уже пенсионного возраста, однако часть из них продолжает работать. Эта группа людей старшего возраста, но не старого. У них еще достаточно энергии, чтобы себя реализовать в жизни. Потому для этой возрастной группы так важна самореализация. В группу «старше 60 лет» входят люди разных старших возрастов (от 60 до 100 лет и, возможно, старше). Аля этой возрастной группы самореализация «важна» $36 \%$ респондентов, как и для предыдущей группы, однако оценка «очень важна» у них меньше - 24\%. Это понятно. В старом возрасте слабеет здоровье, изменяют силы, подтачивают болезни, человек озабочен больше всего тем, чтобы не было хуже, лишь бы не стать бедным, немощным, одиноким. ОАной из их значимых проблем для этой возрастной группы становится забота о своем здоровье.

\section{ЗАКАЮЧЕНИЕ}

В статье рассматривается самореализация наших современников по возрастным интервалам: 19-30 лет; 31-40 лет; 41-50 лет; 51-60 лет; старше 60 лет. Наибольшая самореализация - у молодой возрастной группы. У молодых людей сильная мотивация, умственные способности на пике развития. У работающих людей до пенсионного возраста сохраняется высокая самореализация. У пенсионеров с возрастом самореализация снижается, так как изменяют силы, подтачивают болезни.

\section{СПИСОК АИТЕРАТУРЫ}

Ананьев Б. Г. (1977) О проблемах современного человекознания. М. : Наука. 379 с.

Грибакин А. В. (1985) Жизненный путь как социально-историческое утверждение человека. Иркутск : Иза-во Иркутского ун-та. 199 с.

Зобов, Р. А., Келасьев, В. Н. (2008) Человекознание; самореализация человека / под общ. ред. В. Н. Келасьева. СПб. : ИзА-во С.-Петерб. ун-та. 456 с.

Козлова Т. 3. (2003) Самореализация личности // Социологическая энциклопедия : в 2 т. / глав. ред. В. Н. Иванов. М. Мысль. Т. 2. 861 с.

Козлова, Т. 3. (2017) Самореализация старшего поколения // Социологические исследования. № 1. С. 54-61.

Маслоу, А. Г. (1999) Мотивация личности : пер. с англ. СПб. : Евразия. 479 с. $311 \mathrm{c.}$

Социальное положение и уровень жизни населения России (2015) : стат. сб. М. : Росстат.

Clemens, W., Backes, G. M. (1998) Altern und Gesellschaft, Gesellschaftliche Modernisierung durch Alterns Strukturwandel. Opladen : Leske+Budrich. 288 s.

Botwinick, J. (1967) Cogninive processes in maturity and old age. N. Y.: Springer. 222 p.

Kuhlen, R. G. (1968) Development changes in motivation during the adult years - in Middle age and aging / ed. by B. L. Neugarten. Chicago ; London. 596 p.

Аата поступления: 15.06.2017 2. 


\section{SELF-REALIZATION OF A PERSON BY AGE INTERVALS \\ (BASED ON THE EXAMPLE OF MODERN RUSSIANS) \\ T. Z. KOZLOVA \\ INSTITUTE OF SOCIOLOGY, RUSSIAN ACADEMY OF SCIENCES}

Self-realization of a person is the main goal of their life. The life path of a person is a continuous chain of stages of self-realization. Self-realization of an individual is their actualization in two main spheres of life: profession (work) and family. The object of the study was the age groups of Russian citizens (aged 18 and over): 1) «18-30 years old»; 2) «31-40 years old»; 3) «41-50 years old»; 4) «51-60 years old»; 5) «over 60 years old». Age is an important characteristic of personality. It is an indicator of biological and psychological status of the person, and therefore, to some extent, of their social activity. With age, there is a decrease in mental abilities and a narrowing of the scope of motivation. This thesis is confirmed in the studies of Western scientists (R. Kühlen, B. Newgarten, etc.). The subject of the research is self-realization of a person. Spheres of professional activity are the institutions where the person actualizes themself. The author of the article received an answer to the question of the level of self-realization within different age groups by analysing the representative allRussian sociological research conducted by the Institute of Sociology of the Russian Academy of Sciences at the end of 2016. The sample consisted of 4,000 people. The respondents were asked: «On a 5 -point scale, evaluate the importance of self-realization, manifestation of yourself today.» On the scale from 1 to 5, the values are defined: 1 - «not important»; 4 - «important»; 5 - «very important». Self-realization is determined by the sum of ratings at 4 and 5 . What is the level of self-realization of the individual by age groups? The respondents of the youngest age group «18-30 years old» have strong motivation and mental abilities at the peak of development. They have high self-realization, $87 \%$. The second interval of adult life is a person from 31 to 40 years old. This is the period of the most active realization of the set goals. They also have high self-realization, $83 \%$. The third age period of a person's life is after 50 years old. A person strives to pass their knowledge on to younger people. Self-realization in this age group is $74 \%$. The pre-retirement period ( $\langle 51-60$ years old $»)$ : since retirement for many people is a cause of certain worries, the age group «51-60 years old» has self-realization at $73 \%$. In the age group «60 and older», people's strength is declining, their self-realization is reduced to $56 \%$.

Keywords: age; age intervals; social group; self-realization; personality; motivation; abilities

\section{REFERENCES}

Anan'ev B. G. (1977) O problemakb sovremennogo chelovekoznaniia. Moscow, Nauka. 379 p. (In Russ.).

Gribakin A. V. (1985) Zhiznennyi put' kak sotsial'no-istoricheskoe utverzbdenie cheloveka. Irkutsk, Izd-vo Irkutskogo un-ta. 199 p. (In Russ.).

Zobov, R. A. and Kelas'ev, V. N. (2008) Chelovekoznanie; samorealizatsiia cheloveka / ed. by V. N. Kelas'ev. St. Petersburg, Izd-vo S.-Peterb. un-ta. 456 p. (In Russ.).

Kozlova T. Z. (2003) Samorealizatsiia lichnosti. In: Sotsiologicheskaia entsiklopediia : in 2 vol. / ed. by. V. N. Ivanov. Moscow, Mysl'. Vol. 2. 861 p. (In Russ.).

Kozlova, T. Z. (2017) Samorealizatsiia starshego pokoleniia. Sotsiologicheskie issledovaniia, no. 1, pp. 54-61. (In Russ.).

Maslou, A. G. (1999) Motivatsiia lichnosti : transl. from English. St. Petersburg, Evraziia. 479 p. (In Russ.).

Sotsial' noe polozhenie i uroven' zhizni naseleniia Rossii (2015) : stat. sb. Moscow, Rosstat. 311 p. (In Russ.).

Clemens, W. and Backes, G. M. (1998) Altern und Gesellschaft, Gesellschaftliche Modernisierung durch Alterns Strukturwandel. Opladen, Leske+Budrich. 288 p.

Botwinick, J. (1967) Cogninive processes in maturity and old age. N. Y., Springer. 222 p.

Kuhlen, R. G. (1968) Development changes in motivation during the adult years - in Middle age and aging / ed. by B. L. Neugarten. Chicago; London. 596 p. 
Козлова Татьяна Захаровна - доктор социологических наук, ведущий научный сотрудник отдела методологии социальных процессов Института социологии Российской академии наук. Адрес: 117218, Россия, г. Москва, ул. Кржижановского, д. 24/35, корп. 5. Тел.: +7 (499) 128-85-21. E-mail: tatiana_kozlova@mail.ru

Kozlova Tatyana Zakharovna, Doctor of Sociology, Leading Research Fellow, Institute of Sociology, Russian Academy of Sciences. Postal address: 24/35, Bldg. 5, Krzhizhanovskogo St., Moscow, Russian Federation 117218. Tel.: +7 (499) 128-85-21.E-mail: tatiana_kozlova@mail.ru 